\title{
The common risk factors for progression and mortality in COVID-19 patients: a meta-analysis
}

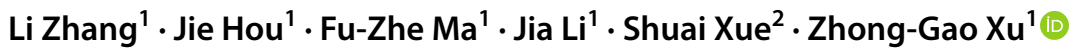

Received: 27 October 2020 / Accepted: 10 January 2021 / Published online: 2 April 2021

(c) The Author(s), under exclusive licence to Springer-Verlag GmbH Austria, part of Springer Nature 2021

\begin{abstract}
Coronavirus disease 2019 (COVID-19), defined by the World Health Organization (WHO), has affected more than 50 million patients worldwide and caused a global public health emergency. Therefore, there is a recognized need to identify risk factors for COVID-19 severity and mortality. A systematic search of electronic databases (PubMed, Embase and Cochrane Library) for studies published before September 29, 2020, was performed. Studies that investigated risk factors for progression and mortality in COVID-19 patients were included. A total 344,431 participants from 34 studies were included in this meta-analysis. Regarding comorbidities, cerebrovascular disease (CVD), chronic kidney disease (CKD), coronary heart disease (CHD), and malignancy were associated with an increased risk of progression and mortality in COVID-19 patients. Regarding clinical manifestations, sputum production was associated with a dramatically increased risk of progression and mortality. Hemoptysis was a risk factor for death in COVID-19 patients. In laboratory examinations, increased neutrophil count, decreased lymphocyte count, decreased platelet count, increased C-reactive protein (CRP), coinfection with bacteria or fungi, increased alanine aminotransferase (ALT) and creatine kinase (CK), increased N-terminal pronatriuretic peptide (NT-proBNP), and bilateral pneumonia in CT/X-ray were significantly more frequent in the severe group compared with the non-severe group. Moreover, the proportion of patients with increased CRP and total bilirubin (TBIL) was also significantly higher in the deceased group than in the survival group. CVD, CKD, sputum production, increased neutrophil count, decreased lymphocyte count, decreased platelet count, increased CRP, coinfection with bacteria or fungi, increased ALT and CK, increased NT-proBNP, and bilateral pneumonia in CT/X-ray were associated with an increased risk of progression in COVID-19 patients. Moreover, the proportion of patients with increased sputum production, hemoptysis, CRP and TBIL was also significantly higher in the deceased group.
\end{abstract}

Handling Editor: Tim Skern.

Shuai Xue and Zhong-Gao Xu contributed equally to this work.

Shuai Xue

xueshuai@jlu.edu.cn

$\triangle$ Zhong-Gao Xu

zhonggao@jlu.edu.cn

1 Department of Nephrology, The First Hospital of Jilin University, Changchun 130021, Jilin, People's Republic of China

2 Department of Thyroid Surgery, The First Hospital of Jilin University, Changchun 130021, Jilin, People's Republic of China

\section{Introduction}

Since December 2019, an outbreak of pneumonia caused by a novel coronavirus has affected China and spread all over the world [1,2]. Coronavirus disease 2019 (COVID19), defined by the World Health Organization (WHO), has infected more than 50 million patients worldwide and caused a global public health emergency [3]. Some patients develop adverse complications and exhibit poor prognosis, and deaths outside of China are increasing persistently. By November 17, 2020, there were 54,771,888 confirmed COVID-19 cases, including more than 1.32 million deaths, and the fatality rate was greater than $10 \%$ in some countries according to the WHO 2020 report $[4,5]$.

Therefore, there is a recognized need to identify risk factors for COVID-19 severity and mortality. Patients with risk factors might be identified earlier, and intensive surveillance or treatment could be administered in advance to improve 
prognosis [6]. Several studies have documented some clinical characteristics and laboratory test values as risk factors for severe and fatal COVID-19 [7-9]. However, various limitations were apparent in these articles, such as reliance on single-center studies and small sample sizes, which might lead to some bias and restrict the generality and applicability of their conclusions. Predictive factors for severe cases and fatal outcome continue to be debated [10]. A meta-analysis of populations from different studies with a larger sample size is needed.

In this article, the clinical characteristics and laboratory test values of COVID-19 patients with severe/fatal illness compared with those with mild/nonfatal illness were compared in 34 studies with 344,431 patients to identify risk factors for severe disease or death in COVID-19 patients. Based on these data, we can predict disease progression and provide intensive surveillance and rapid treatment to effectively improve the prognosis of COVID-19 patients.

\section{Materials and methods}

This meta-analysis was registered in the International Prospective Register of Systematic Reviews (CRD42020179903). This meta-analysis was performed in accordance with the Cochrane Handbook for Systematic Reviews of Interventions guidelines [11].

\section{Search strategy}

The PubMed, EMBASE, and MEDLINE databases were systematically searched from December 1, 2019, to September 29, 2020, with English language limitations. We searched studies using Medical Subject Headings (MeSH) terms, and the main key words included "Covid-19", "Coronavirus Disease 2019", "Wuhan Pneumonia", "SARS-CoV-2", "New Coronavirus Pneumonia", "NCP", "progression", "severity", "bad outcome*", "mortality", "death", and "risk factor* or association*". Additional records were identified manually through other sources.

\section{Inclusion and exclusion criteria}

Inclusion criteria: (1) comparative studies: groups involving severity and non-severity, survival and death; (2) study type: randomized controlled trials, case-control studies, crosssectional studies and cohort studies; (3) study population: patients should be definitely infected with SARS-CoV2, and studies with more than 20 participants were included; (4) parameters: at least one result was reported among basic characteristics, laboratory examinations, comorbidities, and clinical manifestations in the study. Case reports and animal studies were excluded.

\section{Data extraction and quality assessment}

All the search results were imported into the EndNote reference management software (Clarivate Analytics) by L.Z. Duplicate records were removed by the software and hand-checked. Two reviewers (L.Z. and J.L.) independently screened the titles and abstracts of the remaining records for relevance against the protocol criteria and labeled these records as excluded, included, or uncertain. In cases of uncertainty, the full texts were retrieved to review the study in detail. Any disagreements were resolved by consulting a third reviewer. After confirming the included articles, data were extracted by two reviewers (L.Z. and S.X.) independently using a standardized form. Quality assessment of the included studies was conducted according to the NewcastleOttawa Scale [12] score by F.Z.M. and J.H. Any disagreements in the process of data extraction and quality assessment were discussed with other reviewers.

\section{Statistical analysis}

We calculated the odds ratio (OR) with $95 \%$ confidence intervals (CIs) for dichotomous data and mean differences (MDs) with 95\% CIs for continuous data. The I2 statistic was used to assess the heterogeneity test across studies, and $P<0.1$ or $\mathrm{I}^{2}>50 \%$ indicates statistical significance. If no statistical heterogeneity was noted, we used a fixed-effects model; otherwise, we chose a random-effects model. Publication bias was assessed using Egger's regression [13] and Begg's rank correlation analysis [14]. A significance of $P<$ 0.05 indicated the possibility of publication bias [15]. When the $P$-value was less than 0.05 , we adopted a trim-and-fill method to confirm the result. After supplementing several possible missing studies, the meta-analysis was conducted again. If the estimated value of the combined-effect size did not change significantly, the impact of publication bias was not significant [16]. Moreover, we conducted sensitivity analysis to explore sources of heterogeneity. Sensitivity analysis was performed by excluding single studies one at a time to assess its influence on the pooled effects. All statistical analysis was performed using Stata/SE software 15.0 (StataCorp LP) and Review Manager (RevMan) 5.3 (Nordic Cochrane Centre).

\section{Results}

\section{Literature search}

We identified 3212 articles by searching EMBASE, PubMed, and MEDLINE, and four additional records were identified 
using other sources. After excluding 1520 duplicated records and reviewing the titles and abstracts, we had 132 eligible articles. Thirty-four studies were included after screening the full text [7, 9, 17-48]. The process of identification and selection is presented Figure 1.

\section{Study characteristics}

A total of 344,431 participants were included in this metaanalysis. All of the articles were retrospective studies published in 2020. Eighteen studies were performed in Wuhan, 12 studies were conducted outside Wuhan in China, and four studies were done in other countries. The characteristics of the selected studies are presented in Table 1. Thirteen articles included survival and non-survival groups, and 24 included severe and non-severe groups. Subgroups analysis was performed based on severity or mortality. Three studies used the same or a similar population to investigate different aspects. Therefore, data from those studies were not included at the same time in the following comparisons.

COVID-19 severity was classified according to the Guidelines for the Diagnosis and Treatment of COVID-19 by the National Health Commission. In this meta-analysis, patients with mild or/and moderate disease were included in the non-severe group, and patients with severe or/and critical disease were included in the severe group. Moreover, patients in an intensive care unit (ICU) or with $\mathrm{SpO}_{2} \leq$ $90 \%$ or progressive or refractory illness were included in the severe group in several studies.

\section{Study quality}

A summary of the quality assessment of the included studies is presented in Figure S1. With the exception of two trials with a score of 6 , the quality of the selected studies was generally high. All of the scores were greater than 5 and therefore could be included in this meta-analysis.

\section{Basic characteristics}

We compared demographic characteristics between the two groups based on sex (male/total), age $\geq 65$ years, and smoking. These results are shown in Figure 2. Twenty-eight studies reported a male/total ratio among 341,586 subjects. The
Fig. 1 Preferred reporting items for systematic reviews and meta-analyses flow chart of the study selection process, showing the number of studies excluded at each step and the reasons for exclusion from the systematic review and metaanalysis

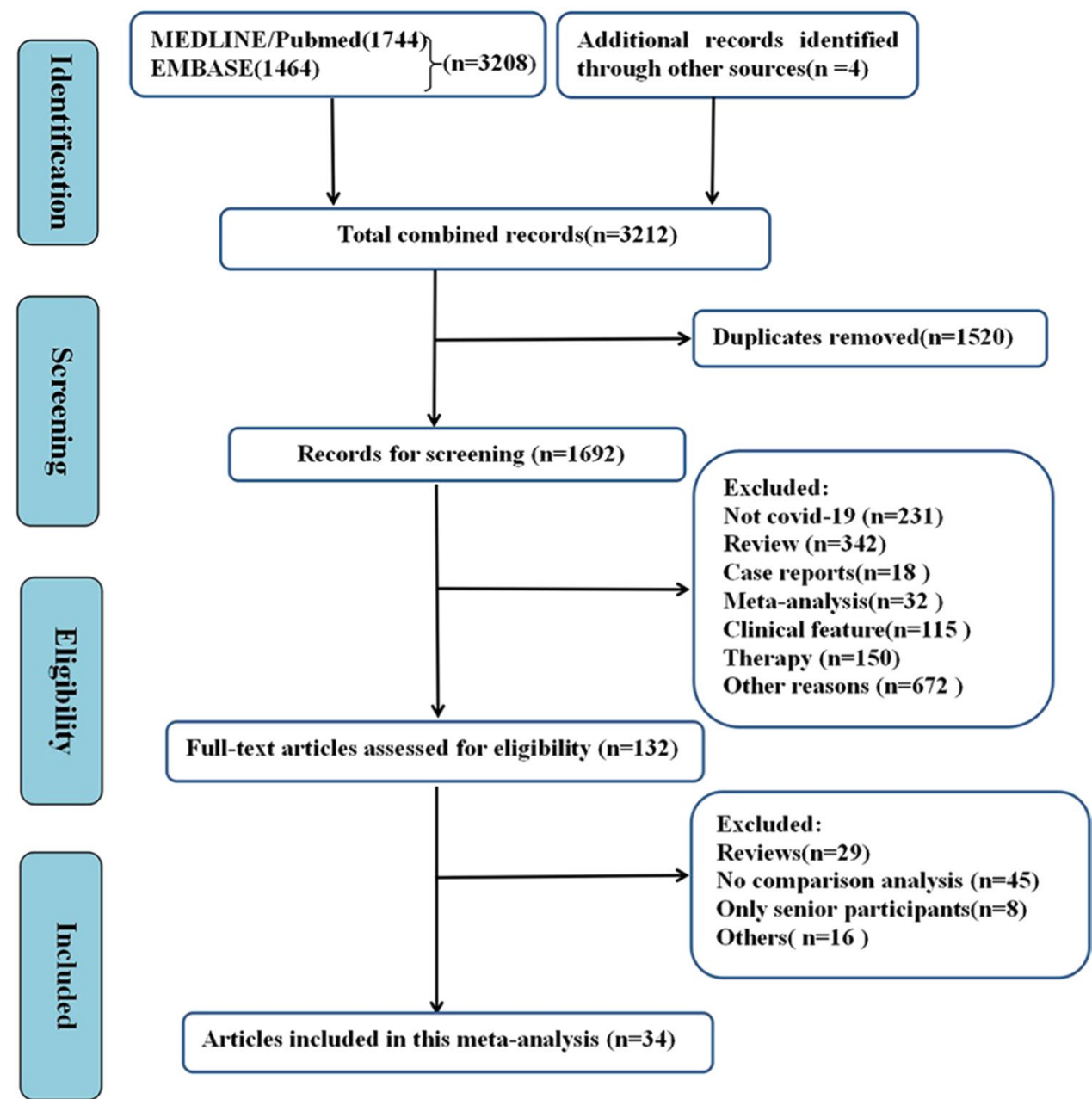


Table 1 Baseline characteristics of the included studies

\begin{tabular}{|c|c|c|c|c|c|}
\hline Author & Region/country & No. of patients & Sex (male/total) & Mean age (SD)/mean (IQR) & NOS \\
\hline Chen $\mathrm{RC}^{*}$ & Throughout China & 1590 & $904 / 1578$ & $69(51-86)$ & 8 \\
\hline Chen XH & Wuhan, China & 48 & $37 / 48$ & $64.6 \pm 18.1$ & 7 \\
\hline Cheng YC & Wuhan, China & 701 & $367 / 701$ & $63(50-71)$ & 7 \\
\hline Du RH & Wuhan, China & 179 & $97 / 179$ & $57.6 \pm 13.7$ & 8 \\
\hline Feng Y & Wuhan,Shanghai and Anhui & 476 & $271 / 476$ & $53(40-64)$ & 8 \\
\hline Guan W* & Throughout China & 1099 & $637 / 1096$ & $47.0(35.0-58.0)$ & 8 \\
\hline Guan WJ* & Throughout China & 1590 & $904 / 1578$ & $48.9 \pm 16.3$ & 7 \\
\hline Huang CL & Wuhan, China & 41 & $30 / 41$ & $49.0(41.0-58.0)$ & 7 \\
\hline Ji D & Anhui,Beijing & 208 & $117 / 208$ & $44.0 \pm 16.3$ & 8 \\
\hline $\mathrm{Li} \mathrm{KH}$ & Chongqing,Jinan & 83 & $44 / 83$ & $45.5(12.3)$ & 7 \\
\hline $\mathrm{Li} \mathrm{XC}$ & Wuhan, China & 548 & $279 / 548$ & $60(48-69)$ & 8 \\
\hline Li Y & Wuhan, China & 25 & $12 / 25$ & N/A & 8 \\
\hline Liu R & Wuhan, China & 119 & $85 / 119$ & N/A & 6 \\
\hline Liu W & Wuhan, China & 78 & $39 / 78$ & $38(33-57)$ & 7 \\
\hline Liu Y & Wuhan, China & 383 & $162 / 383$ & $46(34-61)$ & 7 \\
\hline Mo P & Wuhan, China & 155 & $86 / 155$ & $54(42-66)$ & 7 \\
\hline Qu R & Huizhou, China & 30 & $16 / 30$ & $50.5(36-65)$ & 7 \\
\hline Shi Y & Zhejiang,China & 487 & $259 / 487$ & 46 (19) & 6 \\
\hline Tang N & Wuhan, China & 183 & $98 / 183$ & $54.1 \pm 16.2$ & 7 \\
\hline Tian SJ & Beijing, China & 262 & $127 / 262$ & $47.5(1-94)$ & 7 \\
\hline Wang DW & Wuhan, China & 138 & $75 / 138$ & $56(42-68)$ & 7 \\
\hline Wang RR & Fuyang & 125 & $71 / 125$ & $38.76 \pm 13.799$ & 7 \\
\hline Wang ZL & Wuhan, China & 69 & $32 / 69$ & $42.0(35.0-62.0)$ & 7 \\
\hline Wu CM & Wuhan, China & 201 & $128 / 201$ & $51(43-60)$ & 8 \\
\hline $\mathrm{Wu} \mathrm{J}$ & Yancheng,Fuyang,Wuxi & 280 & $151 / 280$ & $43.12 \pm 19.02$ & 8 \\
\hline Yang AP & Zhejiang,China & 93 & $56 / 93$ & $46.4 \pm 17.6$ & 8 \\
\hline Yang XB & Wuhan, China & 1476 & $776 / 1476$ & $57(47-67)$ & 7 \\
\hline Yuan ML & Wuhan, China & 27 & $12 / 27$ & $60(47-69)$ & 7 \\
\hline Zhang J & Wuhan, China & 663 & $321 / 663$ & $55.6(44-69)$ & 8 \\
\hline Zhou F & Wuhan, China & 191 & $119 / 191$ & $56.0(46.0-67.0)$ & 8 \\
\hline Almazeedi & Kuwait & 1096 & $888 / 1096$ & $41(25-57)$ & 7 \\
\hline Cai QX & Guangdong,China & 383 & $183 / 383$ & N/A & 7 \\
\hline Chang MC & Daegu, South Korea & 106 & $54 / 106$ & $67.6 \pm 15.3$ & 8 \\
\hline Parra-Bracamonte & Mexico & 331,298 & $178,155 / 331,298$ & $44(33-56)$ & 7 \\
\hline
\end{tabular}

N/A, not applicable; SD, standard deviation; IQR, interquartile range; NOS, Newcastle-Ottawa Scale (score)

*Three studies included the same or similar population but investigated different aspects. Therefore, their data were not included at the same time in one comparison.

proportion of males (65.09\%) in the severe and deceased groups was significantly higher than in the non-severe and survival group $(52.45 \%)$ (pooled OR $=1.72,95 \%$ CI 1.68 to $1.75, P<0.00001)$ without heterogeneity $\left(\mathrm{I}^{2}=21 \%\right)$ (Fig. 2A). Furthermore, 10 and 15 studies reported the proportion of patients older than 65 years and those who smoked, respectively, between the two groups (Fig. 2B and C). The proportion of patients in the severe or deceased group was significantly higher than in the non-severe or survival group (both $P<0.00001$ ) (Fig. 2B and C). Smoking patients included current and former smokers.

Fig. 2 Association of general characteristics with progression and mortality in COVID-19. Forest plots are shown for the effects of (A) sex (male/total), (B) age $\geq 65$ years, and (C) smoking. 
A Sex(male/total)

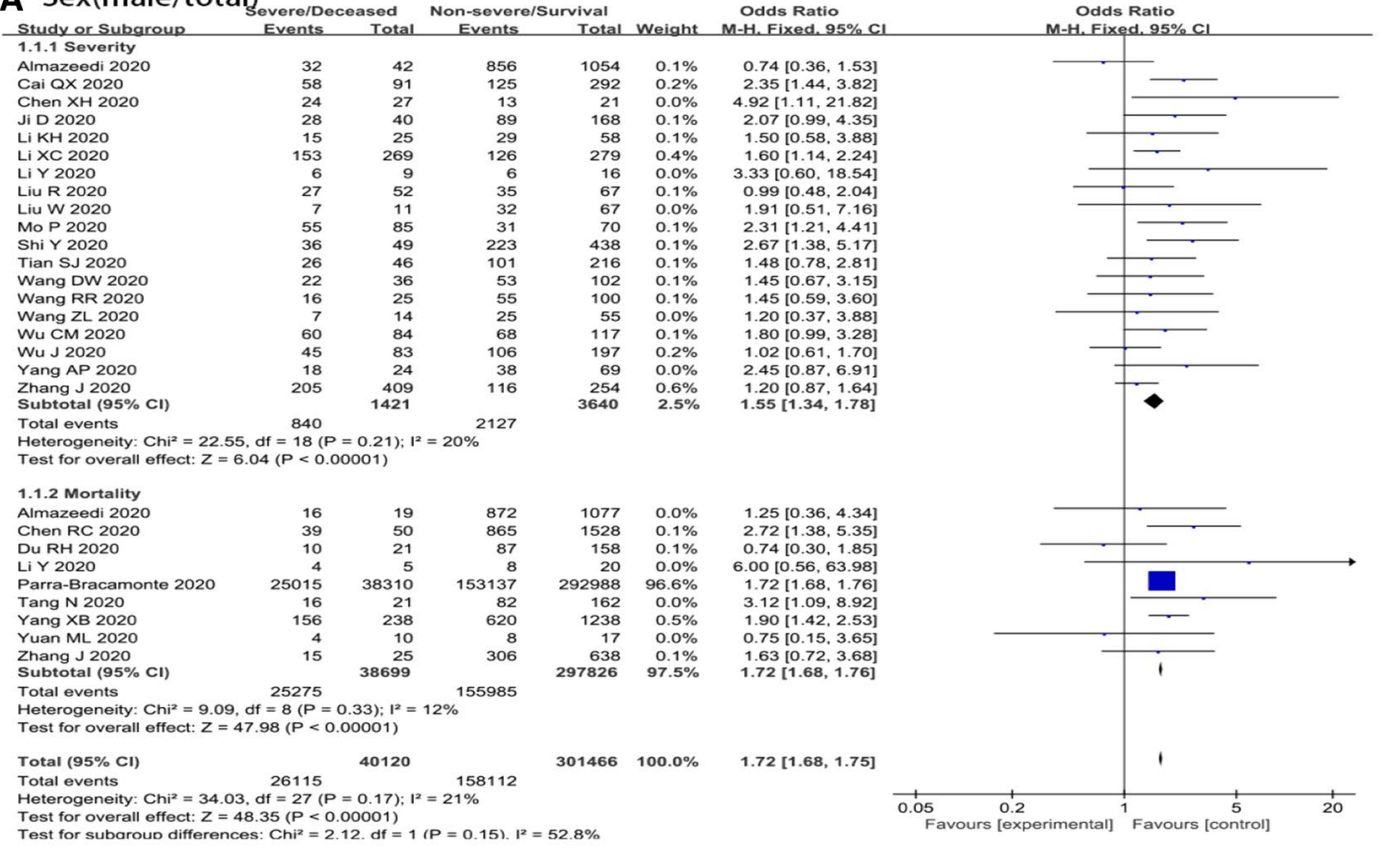

\section{B Age $>=65$ years}

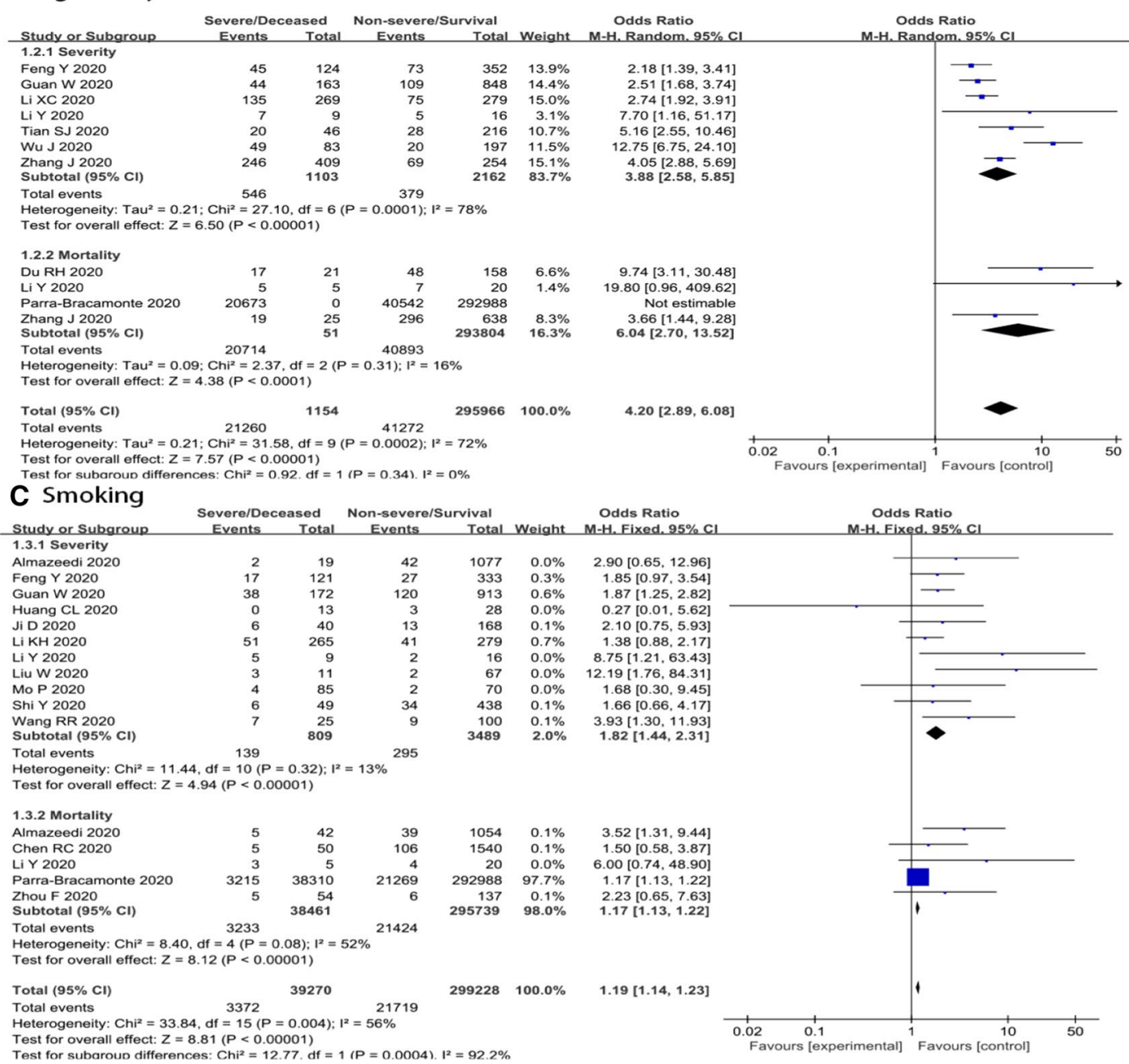




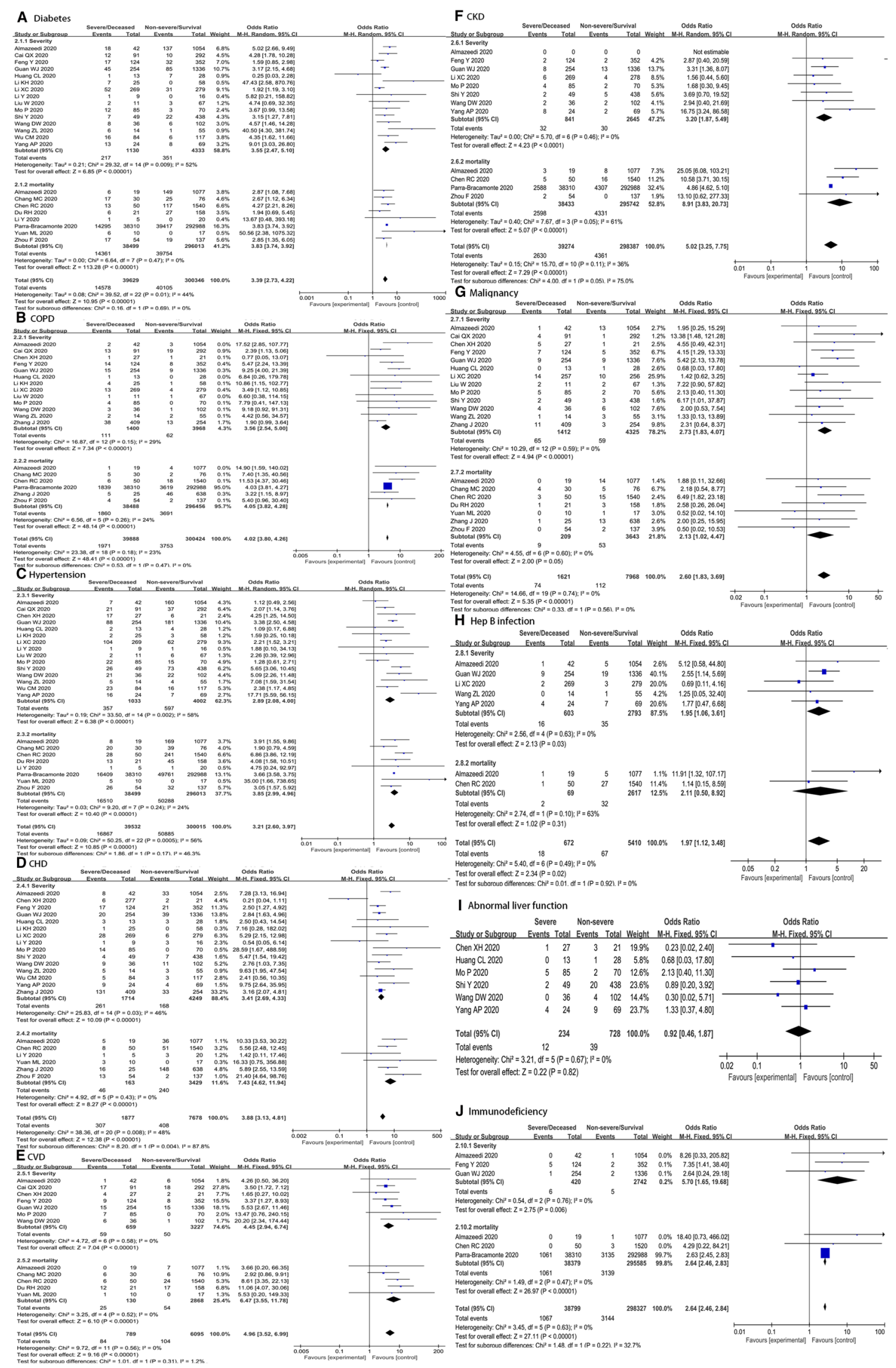


4Fig. 3 Comorbidity risk factors for progression and mortality in COVID-19. Forest plots are shown for the effects of (A) diabetes, (B) COPD, (C) hypertension, (D) CHD, (E) CVD, (F) CKD, (G) malignancy, (H) Hep B infection, (I) abnormal liver function, and (J) immunodeficiency.

\section{Comorbidities}

We compared 10 comorbidities - diabetes, chronic obstructive pulmonary disease (COPD), hypertension, coronary heart disease (CHD), cerebrovascular disease (CVD), chronic kidney disease (CKD), malignancy, hepatitis B virus infection (HepB), abnormal liver function, and immunodeficiency - between the two groups in this study. The outcomes are shown in Figure 3.

Eighteen studies with a total of 339,975 COVID-19 patients were included in the diabetes comorbidity comparison between the two groups. The proportion of patients with diabetes comorbidity was dramatically higher in the severe or deceased group then in the non-severe or survival group (OR $=3.39,95 \%$ CI 2.73 to 4.22 , pooled $P<0.00001)$ without heterogeneity $\left(\mathrm{I}^{2}=44 \%\right)$ (Fig. 3A). Patients with diabetes had a 3.55-fold higher risk of progression and 3.83-fold higher risk of mortality compared with those without diabetes among the SARS-CoV-2-infected population. Similarly, we identified an increased risk of progression and mortality in COVID-19 patients with COPD, hypertension, CHD, CVD, or CKD (all subgroups and total $P$-values $<0.00001$ ) (Fig. 3B-F). Thus, these results confirmed that diabetes, COPD, hypertension, CHD, CVD, and CKD were all associated with an increased risk of progression and mortality in COVID-19 patients.

Moreover, subgroup analysis indicated that malignancy could increase the risk of progression $(\mathrm{OR}=2.73,95 \% \mathrm{CI}$ 1.83 to $4.07, P<0.00001)$ but did not increase the risk of mortality $(\mathrm{OR}=2.13,95 \%$ CI 1.02 to $4.47, P=0.05)$ in COVID-19 patients without obvious heterogeneity (both $\mathrm{I}^{2}$ $=0 \%$ ) (Fig. 3G). Immunodeficiency was also correlated with an increased risk of severity $(P=0.0006)$ and mortality $(P$ $<0.00001$ ) without heterogeneity (Fig. 3J). Furthermore, we found that HepB infection and abnormal liver function were only correlated with severity in COVID-19 patients (Fig. 3H and I).

\section{Clinical manifestations}

We explored 14 common clinical manifestations of COVID19 patients in this analysis (Fig. S1 and Table 2). Thirteen studies with a total of 5407 COVID-19 patients were included in the comparison of sputum production between the two groups. The incidence of sputum production was significantly higher in the severe or deceased group than in the non-severe or survival group (pooled OR $=2.08,95 \%$ CI 1.55 to 2.80 , pooled $P<0.00001$ ). Sputum production was associated with dramatically increased risks of progression and mortality (Fig. S1G). Similarly, we found that the incidence of dyspnea was clearly elevated in the severe and deceased subgroup compared with the non-severe and survival subgroup (severity subgroup: $\mathrm{OR}=5.33,95 \%$ CI 3.36 to $8.45, P<0.00001$; mortality subgroup: $\mathrm{OR}=8.55,95 \%$ CI 2.70 to $27.72, P=0.0003$ ) with significant heterogeneity $\left(\mathrm{I}^{2}=62 \%\right.$ and $\mathrm{I}^{2}=77 \%$, respectively) (Fig. $\left.\mathrm{S} 1 \mathrm{H}\right)$.

We found the proportion of patients with anorexia, fatigue, or shortness of breath to be significantly higher in the severe group than in the non-severe group $(P=$ $0.0004, P=0.04$, and $P<0.00001$, respectively). However, we did not identify similar evidence in the mortality subgroup (Fig. S1B, C, and J). The results also showed that the proportion of patients with hemoptysis was significantly higher in the survival group than in the nonsurvival group $(P<0.00001)$. Moreover, compared with the non-severe group, the proportion of patients with fever, pharyngalgia, cough, hemoptysis, dizziness, or nausea/ vomiting was higher, and the proportion with myalgia/ arthralgia, diarrhea, or headache was lower in the severe group; however, the differences were not statistically significant. Similarly, compared with the survival group, the proportion of patients with cough, myalgia/arthralgia, diarrhea, headache, or nausea/vomiting was higher, and the proportion of patients with fever was lower in the deceased group. However, these differences were not statistically significant (Fig. S1 and Table 2).

\section{Laboratory tests}

We investigated 20 common laboratory examinations of COVID-19 patients in this analysis. Given that there were too many results to be presented, we divided laboratory results into four aspects as follows: Laboratory values greater than the upper limit of the locally defined reference range were regarded as elevated, and those lower than the lower limit were considered decreased.

\section{Routine blood tests}

In total, 13 studies with 5252 participants investigated the proportion of patients with elevated white blood cell (WBC) counts in each of the two groups of COVID-19 patients. The proportion of patients with elevated WBC counts was 
Table 2 Results of meta-analysis of the clinical manifestations

\begin{tabular}{|c|c|c|}
\hline Clinical manifestation & OR $(95 \%$ CI $)$ & $P$-value \\
\hline \multicolumn{3}{|l|}{ Severity subgroup } \\
\hline Fever & $1.33(0.83$ to 2.12$)$ & 0.23 \\
\hline Anorexia & 2.78 (1.58 to 4.89$)$ & 0.0004 \\
\hline Fatigue & 1.22 (1.01 to 1.47$)$ & 0.04 \\
\hline Myalgia/arthralgia & $0.77(0.47$ to 1.26$)$ & 0.30 \\
\hline Pharyngalgia & $1.24(0.82$ to 1.88$)$ & 0.30 \\
\hline Cough & $1.26(0.88$ to 1.80$)$ & 0.22 \\
\hline Sputum & 2.11 (1.40 to 3.19$)$ & 0.0004 \\
\hline Dyspnea & $5.33(3.36$ to 8.45$)$ & $<0.00001$ \\
\hline Hemoptysis & $3.89(0.95$ to 15.91$)$ & 0.06 \\
\hline Shortness of breath & $6.63(3.05$ to 14.41$)$ & $<0.00001$ \\
\hline Diarrhea & $0.95(0.75$ to 1.22$)$ & 0.71 \\
\hline Nausea/vomiting & $1.11(0.76$ to 1.62$)$ & 0.58 \\
\hline Headache & $0.79(0.56$ to 1.12$)$ & 0.18 \\
\hline Dizziness & $2.44(0.83$ to 7.14$)$ & 0.10 \\
\hline \multicolumn{3}{|l|}{ Mortality subgroup } \\
\hline Fever & $0.81(0.47$ to 1.38$)$ & 0.43 \\
\hline Fatigue & $1.40(0.98$ to 2.00$)$ & 0.06 \\
\hline Myalgia /arthralgia & $1.22(0.77$ to 1.95$)$ & 0.39 \\
\hline Cough & $1.10(0.56$ to 2.17$)$ & 0.78 \\
\hline Sputum & $1.98(1.31$ to 3.01$)$ & 0.001 \\
\hline Dyspnea & 8.55 (2.70 to 27.12$)$ & 0.0003 \\
\hline Hemoptysis & $165.82(22.73$ to 1209.81$)$ & $<0.0001$ \\
\hline Shortness of breath & $4.65(0.42$ to 51.96$)$ & 0.21 \\
\hline Diarrhea & $1.03(0.54$ to 1.95$)$ & 0.93 \\
\hline Nausea/vomiting & $1.52(0.74$ to 3.11$)$ & 0.25 \\
\hline Headache & $1.43(0.81$ to 2.53$)$ & 0.22 \\
\hline Dizziness & $1.17(0.15$ to 9.02$)$ & 0.88 \\
\hline
\end{tabular}

significantly higher in both the severe and mortality subgroups $(\mathrm{OR}=3.22,95 \%$ CI 2.03 to $5.11, P<0.00001$; $\mathrm{OR}=6.87,95 \% \mathrm{CI} 4.59$ to $10.29, P<0.00001$, respectively) without statistical heterogeneity $\left(\mathrm{I}^{2}=50 \%\right.$ and $\mathrm{I}^{2}$ $=5 \%$ respectively) (Fig. 4A). Moreover, the proportion of patients with a reduced WBC count was lower in the severe/ deceased group than in the non-severe/survival group, but the results were only statistically significant for the mortality subgroup (OR $=0.45,95 \% \mathrm{CI} 0.21$ to $0.96, P=0.04)$ (Fig. 4B). Similarly, the rates of increased neutrophil counts
Fig. 4 Routine blood test risk factors for progression and mortality in COVID-19. Forest plots are shown for the effects of (A) elevated WBC, (B) decreased WBC, (C) elevated neutrophils, (D) decreased neutrophils, (E) decreased platelets, and (F) decreased lymphocytes.

and reduced lymphocyte counts were significantly higher in both the severe and deceased groups than in the non-severe and survival groups (both pooled $P<0.00001$, Fig. $4 \mathrm{C}$ and $\mathrm{F}$ ); however, some heterogeneity was noted in the subgroups (neutrophil increased: severity subgroup $\mathrm{I}^{2}=61 \%$; lymphocyte decreased: mortality subgroup $\mathrm{I}^{2}=88 \%$ ). Compared with the non-severe group, the proportion of patients with a reduced platelet count was significantly increased, and the proportion of patients with reduced neutrophil levels was lower in the severe group $(P=0.01, P=0.04$, and $P=0.03$, respectively). However, we did not identify similar evidence in the mortality subgroup (Fig. 4D and E).

\section{Infection-related results}

Four infection-related factors - C-reactive protein (CRP), procalcitonin (PCT), IL-6, and coinfection with another pathogen - were investigated in this study (Fig. 5). The proportion patients with elevated CRP, elevated PCT, and coinfection with bacteria or fungi was significantly higher in the severe group than in the non-severe group $(P<0.00001$, $P<0.00001, P=0.03$, and $P=0.01$, respectively) without significant heterogeneity (Fig. 5A, B and D). The proportion of patients with elevated CRP or PCT was also significantly higher in deceased group than in the survival group $(P=$ 0.003 and $P=0.005$, respectively), but heterogeneity was noted $\left(\mathrm{I}^{2}=73 \%\right.$ and $\mathrm{I}^{2}=80 \%$, respectively) (Fig. 5A and $\mathrm{B}$ ). Sufficient evidence was not enough available to determine the effect of IL-6, a common inflammatory cytokine, on the risk of progression and mortality (Fig. 5C).

\section{Blood biochemistry}

Six common blood biochemistry results were studied in this meta-analysis (Fig. 6). The proportion of patients with increased aspartate aminotransferase (AST), alanine aminotransferase (ALT), creatine kinase (CK), and serum creatinine (sCr), was significantly higher in the severe/deceased 


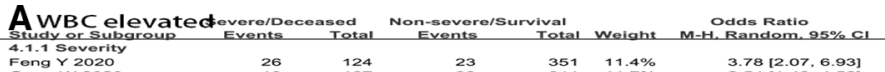

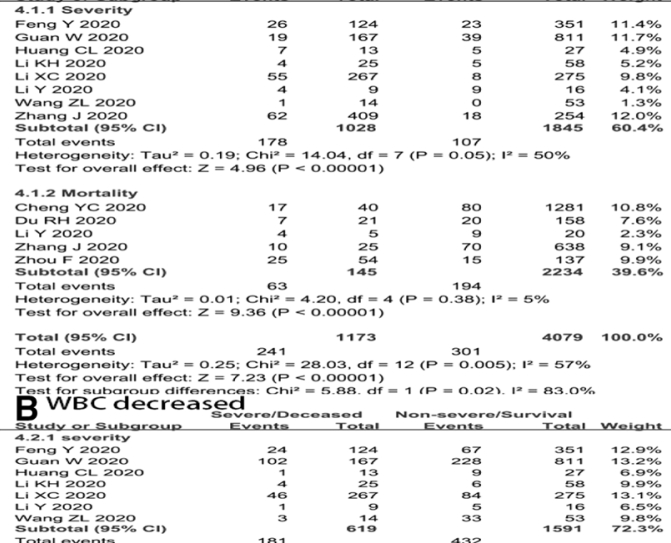

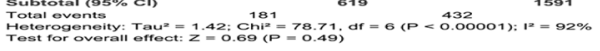

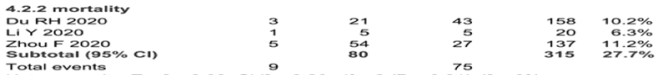

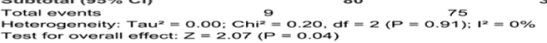

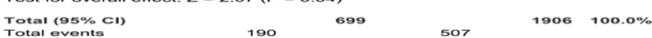

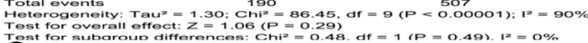

C' Neutrophil elevated

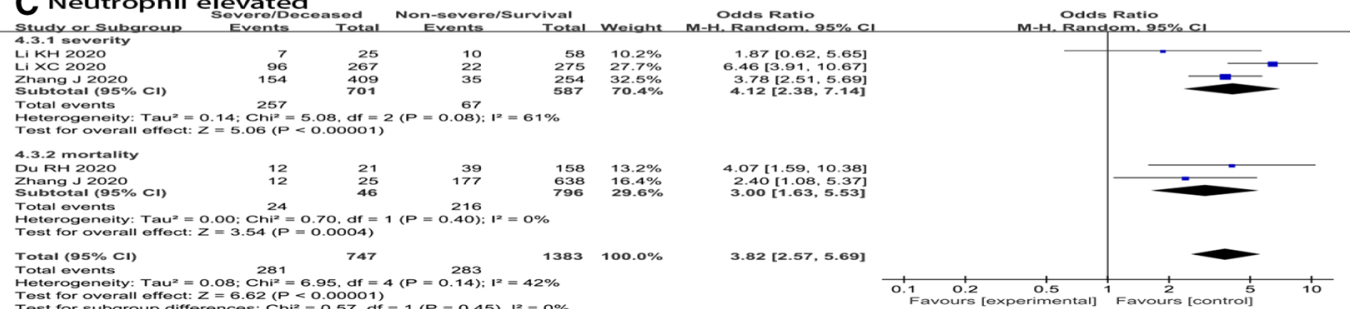

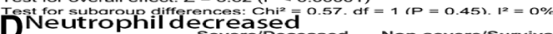

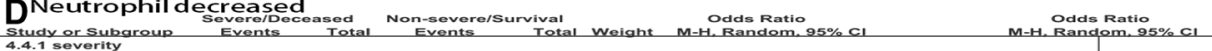

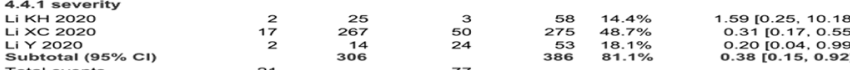

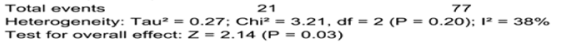

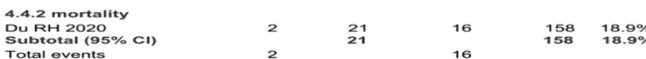

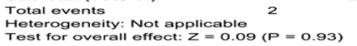

Total (95\% C1) $\quad 327 \quad 544 \quad 100.0 \%$

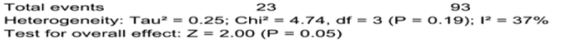

Elatel decreased

Eludy a Odas Ratio

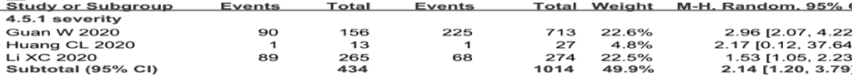

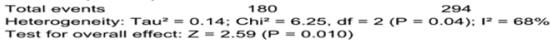

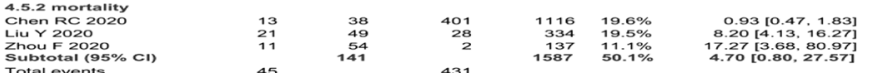

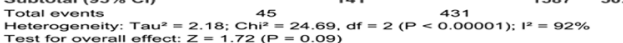

Total (95\% C1) $575 \quad 2601 \quad 100.0 \%$

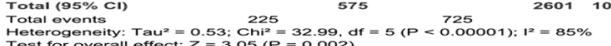

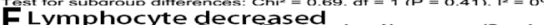

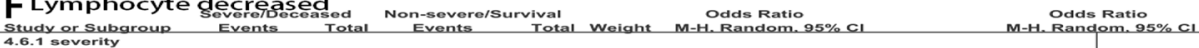

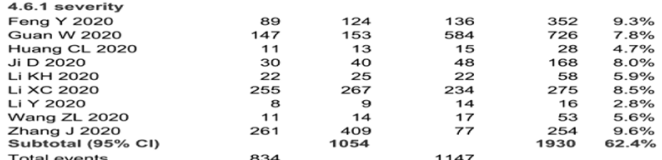

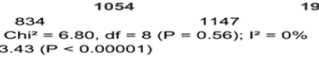

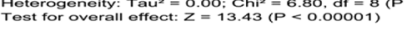

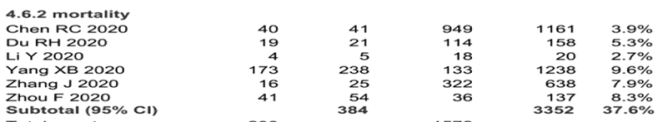

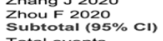

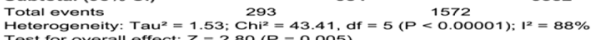

$\begin{array}{lllll}\text { Total }(95 \% \mathrm{Cl}) & 1438 \quad 2710 & 5282 & 100.0 \%\end{array}$

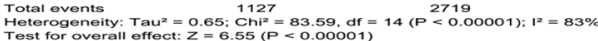

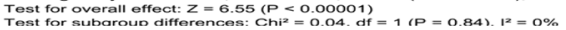

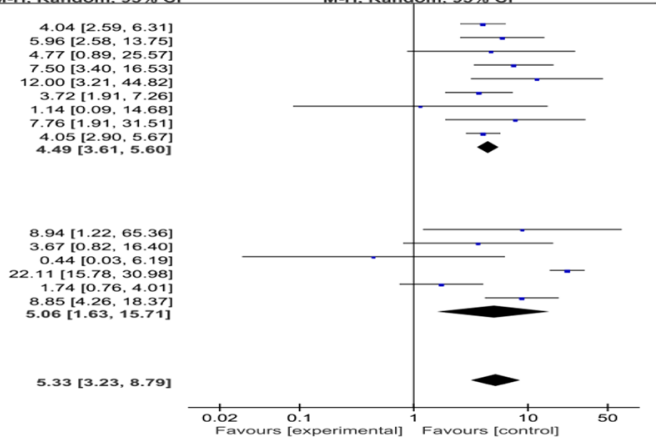




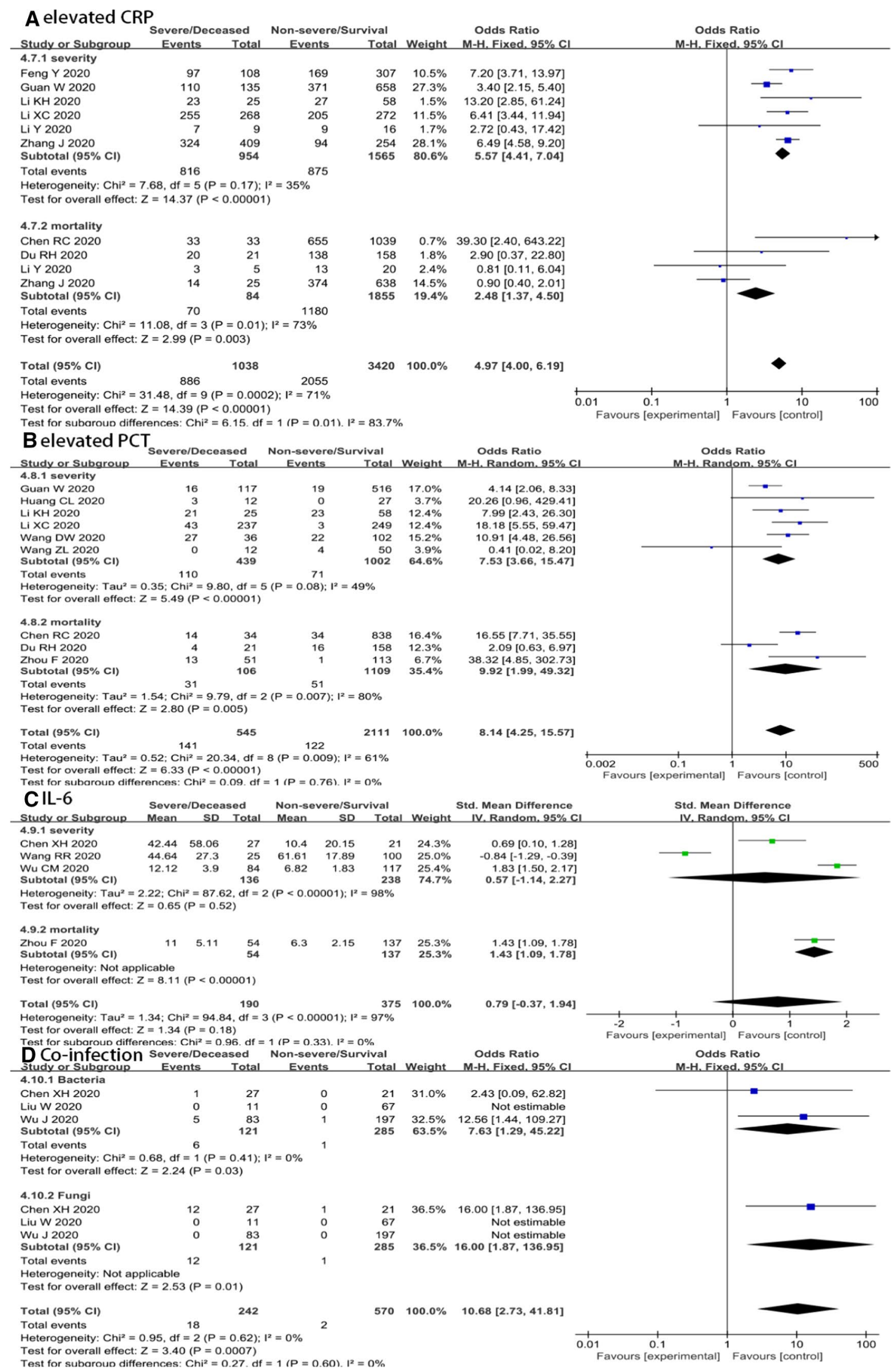


४Fig. 5 Infection-related risk factors for progression and mortality in COVID-19. Forest plots are shown for the effects of (A) elevated CRP, (B) elevated PCT, (C) elevated IL-6, (D) and co-infection.

group than in the non-severe/survival group (pooled results: AST: $\mathrm{OR}=2.78,95 \%$ CI 2.24 to $3.46, P<0.00001$; ALT: $\mathrm{OR}=1.74,95 \%$ CI 1.43 to $2.13, P<0.00001 ; \mathrm{CK}: \mathrm{OR}=$ 2.03, $95 \%$ CI 1.40 to $2.96, P=0.0002$; sCr: $\mathrm{OR}=3.80$, 95\% CI 2.32 to $6.20, P<0.00001$ ) (Fig. 6A, B, E, and F). In addition, lactate dehydrogenase (LDH) and total bilirubin (TBIL) levels were assessed. The results suggest that increased LDH is associated with a higher risk of progression $(\mathrm{OR}=4.12,95 \% \mathrm{CI} 2.88$ to $5.90, P<0.00001)$ but not mortality; however, increased TBIL is associated with a higher risk of mortality $(\mathrm{OR}=2.58,95 \% \mathrm{CI} 1.14$ to $5.83, P$ $<0.00001$ ) but not progression (Fig. 6C and D).

\section{Other results}

The proportion of elevated N-terminal pronatriuretic peptide (NT-proBNP) or D-dimer was significantly higher in the severe/deceased group than in the non-severe/survival group (pooled OR $=4.57,95 \%$ CI 2.68 to $7.81, P<0.00001$; OR $=3.19,95 \%$ CI 2.53 to $4.02, P<0.00001$, respectively) without significant heterogeneity $\left(\mathrm{I}^{2}=0 \%\right.$ and $\mathrm{I}^{2}=49 \%$, respectively) (Fig. 7B and $\mathrm{C}$ ). We found that increased highsensitivity cardiac troponin I (Hs-cTnI) is associated with a higher risk of mortality $(\mathrm{OR}=14.40,95 \%$ CI 2.45 to 84.54 , $P=0.003$ ) but not severity (Fig. 7A); however, bilateral pneumonia in CT/X-ray is associated with a higher risk of severity ( $\mathrm{OR}=2.27,95 \%$ CI 1.13 to $4.58, P=0.02)$ but not mortality, with statistical significance despite some degree of heterogeneity $\left(\mathrm{I}^{2}=62 \%\right.$ and $\mathrm{I}^{2}=86 \%$, respectively) (Fig. 7D).

\section{Publication bias}

Egger's regression analysis and Begg's rank correlation analysis were performed to assess publication bias (Table S2). With the exception of dyspnea and smoking, the $P$-values for all factors were greater than 0.05 , indicating the absence of publication bias. To confirm the publication bias for dyspnea, we adopted the trim-and-fill method (Fig. 8). After assessing five studies, the $P$-value was less than 0.0001 , which is the same as the previous result; however, the OR $(95 \% \mathrm{CI})$ changed from $-1.809(-2.251,-1.366)$ to 0.260 $(0.160,0.422)$, suggesting publication bias. Similarly, we did funnel plot analysis for smoking, showing asymmetry, indicating publication bias (Fig. 3).

\section{Sensitivity analysis}

Although subgroup analysis was used in this study, heterogeneity was still noted for some factors. We performed leaveone-out sensitivity analysis to identify possible explanations for heterogeneity (Table S3). High heterogeneity with an $\mathrm{I}^{2}$ $>50 \%$ and $P<0.05$ was found in the analysis of some risk factors. Additionally, after the removal of each study from the analysis, similar results were obtained, and the heterogeneity of most risk factors changed significantly. The high heterogeneity was not reduced by sensitivity analysis in three comparisons (diabetes, decreased WBC, and LDH) in the severity or mortality group. However, after the removal of each study from the analysis of diabetes, decreased WBC, and $\mathrm{LDH}$, the results were stable.

\section{Discussion}

Within several months, COVID-19 spread across the world and became a serious health threat to all humans [3]. The number of critical patients and deaths increased substantially, although the majority of infected individuals survived [49]. Early diagnosis and treatment are essential in severe cases, which underscores the importance of identifying predictive factors of disease progression and death. Several studies have investigated risk factors for critical/fatal COVID-19 with a limited number of patients [7, 10]. However, these studies yielded conflicting results due to small sample sizes. To provide less-biased estimates on this specific topic, a meta-analysis, which is an objective, quantitative method, was employed.

Recently, a meta-analysis from China that included 13 studies from Jan 1, 2020, to Mar 20, 2020, was published [10]. Some risk factors for critical/fatal COVID-19 cases were identified. However, another 21 original studies on this topic were published subsequently within several months. An updated meta-analysis is needed to explore new risk factors for critical/fatal COVID-19. In addition to common risk factors, such as male sex, age over 65 years, smoking, hypertension, diabetes, cardiovascular disease, and respiratory diseases, shortness of breath or dyspnea, WBC, AST, Cr, PCT, LDH, hs-cTnI and D-dimer, we also identified some new factors in this study.

Regarding comorbidities, diabetes was one leading risk factor for progression in COVID-19 patients [50]. Zhu et al. also found that well-controlled blood glucose levels correlated with a reduced risk of detrimental complications and all-cause mortality in subjects with COVID-19 and pre-existing diabetes [51]. Uncontrolled glycemia and diabetes have been reported as important predictors 


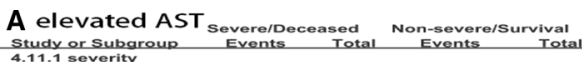

Guan $w 2020$
Gut

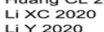

Lir 2020

Zhang 2020 (1)

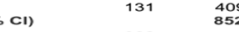

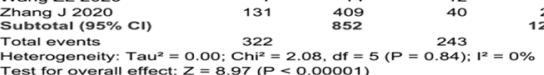

4.11.2 mortality

Con
Chen R 202020
LiY 2020

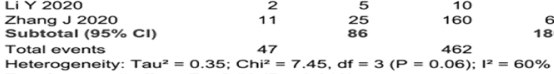

Test for overall

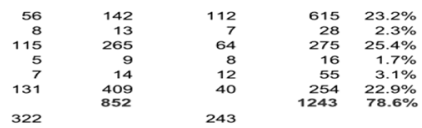

Odds Ratio

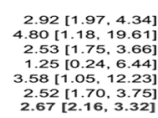

Total (95\% Cl)

$\begin{array}{rrrrr}24 & 35 & 245 & 955 & 8.2 \% \\ 10 & 21 & 47 & 158 & 5.3 \% \\ 2 & 5 & 10 & 20 & 1.2 \% \\ 11 & 25 & 160 & 638 & 6.7 \% \\ & 86 & & 1801 & 21.4 \%\end{array}$

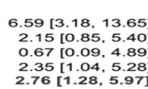

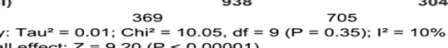

Test for overall effect: $Z=9.20(P=0.00001) \quad 1(P=0.94), 1^{2}=0 \%$

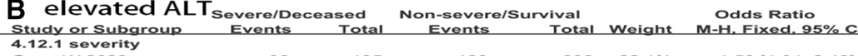

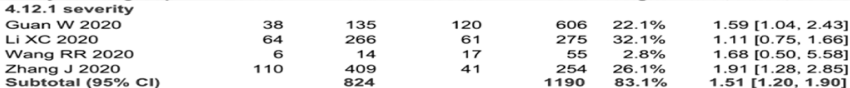

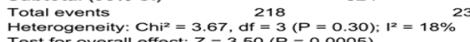

4.12.2 mortality

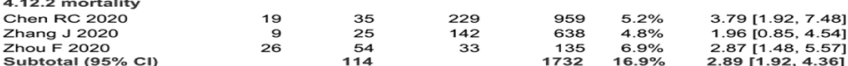

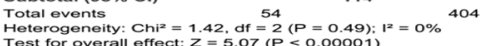

Total $(95 \% \mathrm{Cl}) \quad 938$

Total events
Heterogeneity: Chir $=12.49 .272 \quad$ df $=6(P=0.05): 12=52 \%$

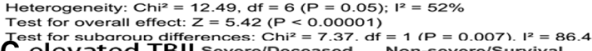

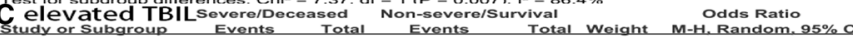

4.13 .1 severity
Guan $W 2020$

Guan $w 2020$
Li $\times C 2020$

Subtotal ( $95 \% \mathrm{Cl}$ )

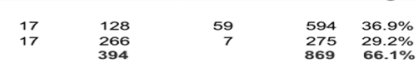

Heterogentity: Tau $^{2}=0.05: \mathrm{Chi}^{2}=1.36$. df $=1(P=0.24): 1^{2}=26 \%$
Test for overall effect: $Z=1.81(P=0.07)$

4.13.2 mortality

Chen RC $202 \mathrm{O}$
Subtotal
$95 \% \mathrm{Cl}$

$14 \quad 3$

106

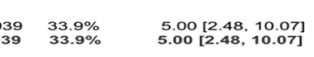

Hetergeneity: Not applicable
Test for overail effect:
D

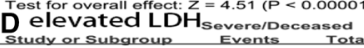

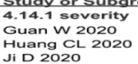

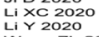

Liv 2020
wang 202020
zang $J 2020$

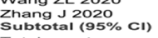

$\begin{array}{rl}253 & 40 \\ 869 & 0\end{array}$

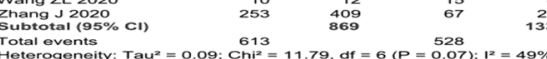

4.14.2 mortality

Chen $R C 2020$
Lirazo20
zhang 2020

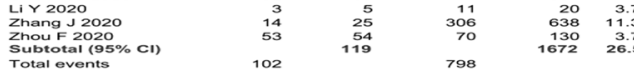

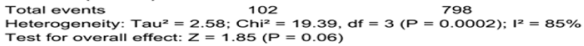

Total $195 \% \mathrm{Cl}$

$\begin{array}{lllllll}715 & 988 & & & 326 & 3009 & 100.0 \%\end{array}$

Hoterogenoity: $\mathrm{Tau}^{2}=0.26 ; \mathrm{Ch}^{2}=29.45$, df $=10(P=0.001) ; \mathrm{l}^{2}=66 \%$

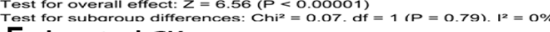

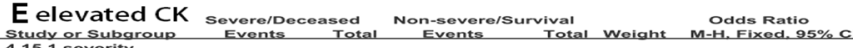

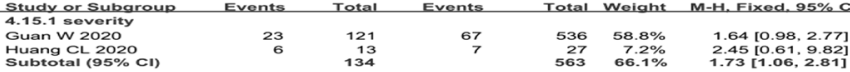

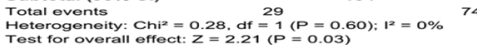

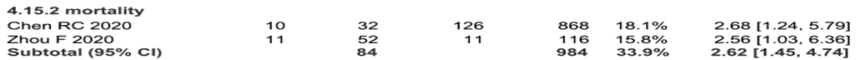

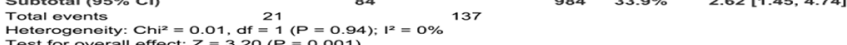

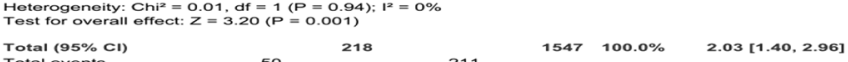

Total $(95 \% \mathrm{Cl})$

218

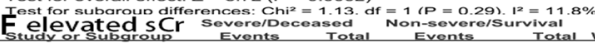

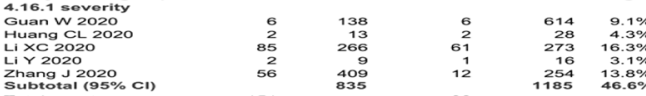

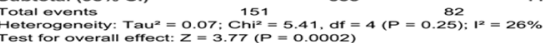

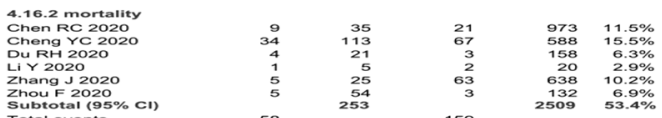

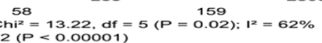

Toet for overail offoct: $2-4.42$ (P) $<8$.

Total (195\% C1)

1088

$3694 \quad 100.0 \%$

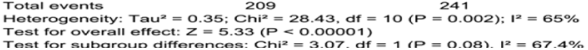
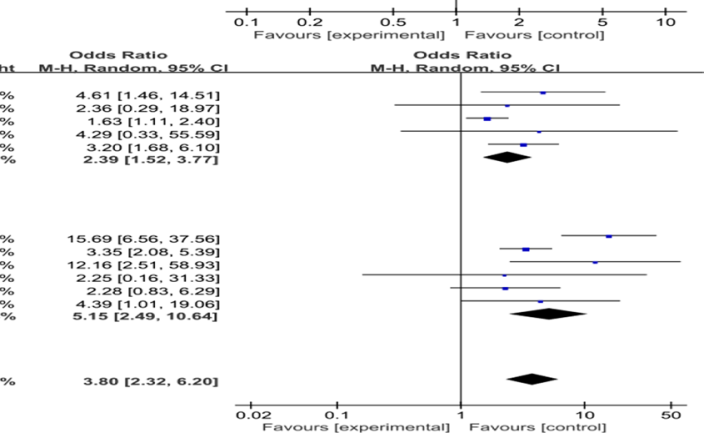
4Fig. 6 Blood biochemistry test risk factors for progression and mortality in COVID-19. Forest plots are shown for the effects of (A) elevated AST, (B) elevated ALT, (C) elevated TBIL, (D) elevated LDH, (E) elevated CK, and (F) elevated $\mathrm{sCr}$.

of severity and death in subjects infected with SARS-CoV, H1N1 influenza virus, and MERS-CoV [52-54]. In addition, CVD and CKD were associated with an increased risk of progression and mortality in COVID-19 patients. A growing body of evidence shows that SARS-CoV-2 attaches to the cell membrane and attacks host cells via the ACE2 receptor [55, 56]. ACE2 receptors, which are mainly distributed in the cardiovascular system, lung, kidneys, and colon, have also been detected in glial cells and neurons in the brain; thus, these sites are potential targets of SARS-CoV-2 [57, 58]. ACE2 expression in brain and kidney cells is downregulated by mechanisms such as internalization, shedding, and viral replication [59]. An inflammatory response and exudation of immune cells are induced via increased Ang II concentrations, resulting in a cytokine storm and target-organ damage $[60,61]$. If patients with CVD are infected with SARS-CoV-2, bleeding from cerebral capillaries due to endothelial ruptures could have fatal consequences [62]. The prevalence of acute kidney injury among COVID-19 patients is approximately $0.5 \%$. The available data suggest that cytokine damage, organ crosstalk, and systemic effects might represent potential mechanisms of kidney injury in COVID-19 [63, 64]. Kidneys from CKD patients can experience a second hit via viral infection, and these patients are more likely to develop to renal failure [63]. In addition, malignancy and immunodeficiency increase the risk of disease progression or mortality. Compared to a $2.3 \%$ fatality rate for all COVID-19 patients, the fatality rate for infected cancer patients in China is $28.6 \%$ [65]. Patients with cancers are at an increased risk of severe complications of respiratory viruses because they are frequently immunosuppressed as a result of their disease and treatment [66]. The immune response plays important role in virus elimination and disease progression. For patients with malignancy or immunodeficiency, COVID-19 more often results in critical/fatal cases [67, 68].

Regarding clinical manifestations, sputum production was associated with a dramatically increased risk of progression and mortality. Exudation is a clinical manifestation of inflammation [69], and the volume of exudate is positively correlated with the severity of inflammation. We also found that the incidence of anorexia, fatigue, and shortness of breath was significantly higher in the severe group than in the non-severe group. In an European investigation, that also identified infection-related pulmonary symptoms such as dyspnea, fever were more prevalent in patients with moderate-to-severe COVID-19 [70]. Notably, except for dyspnea, we found hemoptysis to be another important risk factor for mortality. Thus, patients with hemoptysis should be given particular attention.

Regarding laboratory examination, several test values are associated with severity and mortality of COVID- 19 . Increased neutrophil count, decreased lymphocyte count, decreased platelet count, increased CRP, coinfection with bacteria or fungi, increased ALT and CK, increased NT-proBNP, and bilateral pneumonia in CT/X-ray were significantly higher in the severe group than in the nonsevere group. Moreover, the proportion of patients with increased CRP and TBIL was also significantly higher in the deceased group than in the survival group. When the body is infected or the tissue is damaged, CRP plasma levels increase rapidly as an acute protein indicator [71]. These increased levels increase phagocytosis and activate the complement cascade [72]. Moreover, damaged, necrotic, and apoptotic tissues and cells, as well as the pathogen, are eliminated by CRP. The CRP concentration is a reflection of the body's response to infection [73]. Increased NT-proBNP and ALT indicate impaired cardiac function, and increased TBIL indicates impaired liver function. Coinfection with bacteria or fungi and bilateral pneumonia in CT/X-ray were associated with COVID-19 severity. This is consistent with the results of Li et al., showing that initial CT scores may be useful to stratify patients [74]. All of the risk factors are helpful for identifying possible severe cases and are potentially valuable for decisions regarding allocation of medical resources.

\section{Strengths and weaknesses}

To the best of our knowledge, this is the first updated metaanalysis to assess all of the common risk factors for progression and mortality in COVID-19 patients using a large study sample. In this study, more confounding factors were adjusted, and more risk factors were found for the first time. High heterogeneity was found in the analysis of some risk factors, and the majority of factors were compensated by sensitivity analysis. Some results (decreased WBC and LDH in severe and fatal cases as well as dizziness) should be interpreted with caution given the limited number of included articles and high heterogeneity. Further high-quality studies are needed to verify these results.

This meta-analysis has some potential limitations. First, the source of heterogeneity for some risk factors was not identified by sensitivity analysis. Second, the small sample size of patients hindered the implementation of meta-regression analysis. Third, the nonrandomized and retrospective 


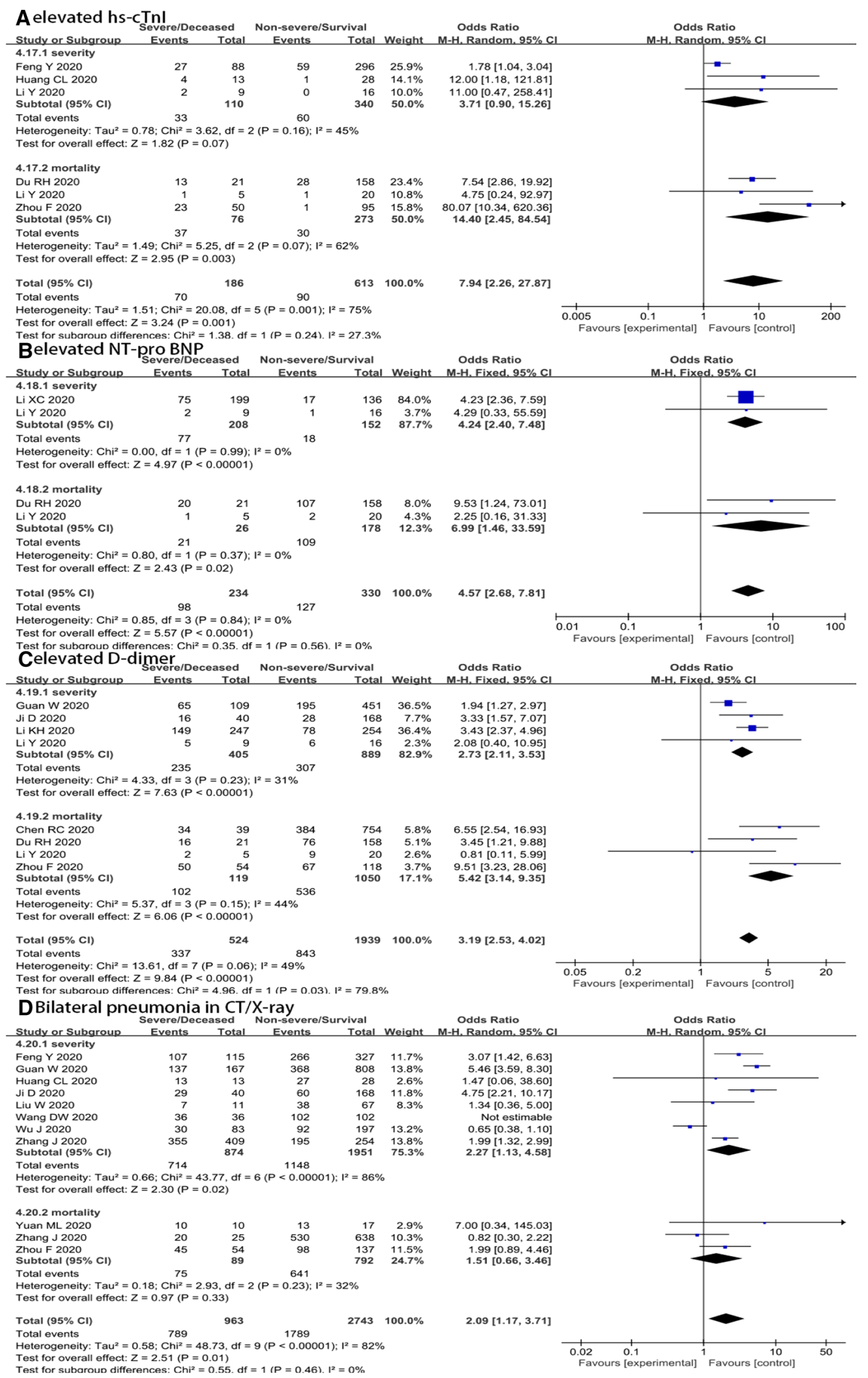


4Fig. 7 Other lab examination risk factors for progression and mortality in COVID-19. Forest plots are shown for the effects of (A) elevated hs-cTnl, (B) elevated NT-pro BNP, (C) elevated D-dimer, and (D) bilateral pneumonia in $\mathrm{CT} / \mathrm{X}$-ray.

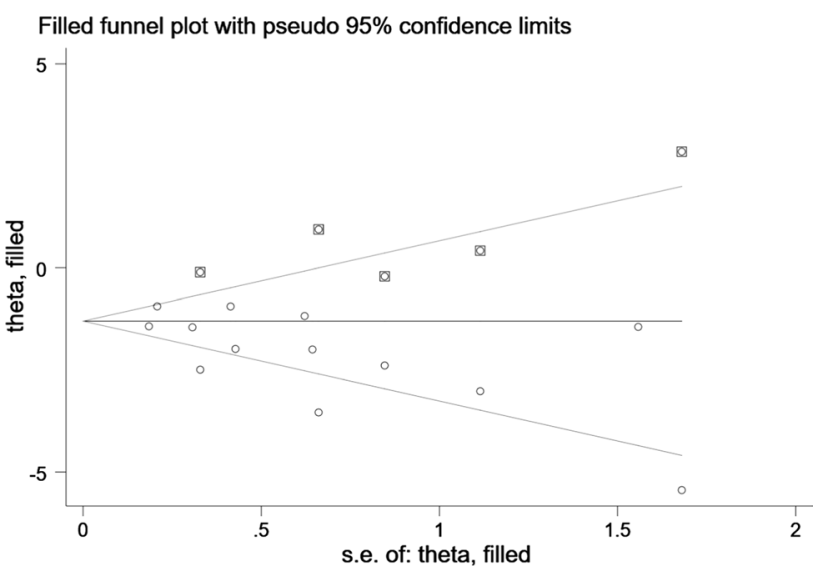

Fig. 8 Trim-and-fill analysis for the publication bias for dyspnea

nature of all studies should be taken into consideration as a source of bias. Randomized controlled trials are warranted in the future to provide high-quality evidence.

\section{Conclusions}

Some new risk factors were identified in our updated metaanalysis. Regarding comorbidities, CVD, CKD, CHD, and malignancy were associated with an increased risk of progression and mortality in COVID-19 patients. Regarding clinical manifestations, sputum production was associated with a dramatically increased risk of progression and mortality. Hemoptysis was a risk factor for death in COVID-19 patients. In laboratory examinations, increased neutrophil count, decreased lymphocyte count, decreased platelet count, increased CRP, coinfection with bacteria or fungi, increased ALT and CK, increased NT-proBNP, and bilateral pneumonia in CT/X-ray were significantly higher in the severe group than in the non-severe group. Moreover, the proportion of patients with increased CRP and TBIL was also significantly higher in the deceased group than in the survival group.

Supplementary Information The online version contains supplementary material available at https://doi.org/10.1007/s00705-021-05012-2.

Author contributions All named authors meet the International Committee of Medical Journal Editors (ICMJE) criteria for authorship for this article, take responsibility for the integrity of the work as a whole, and have given their approval for this version to be published.

Funding No funding or sponsorship was received for this study or publication of this article.

\section{Declarations}

Conflict of interest The authors declare that they have no conflict of interest.

Compliance with ethics guidelines This article is based on previously conducted studies and does not contain any studies with human participants or animals performed by any of the authors.

\section{References}

1. Chan JF-W, Yuan S, Kok K-H, To KK-W, Chu H, Yang J et al (2020) A familial cluster of pneumonia associated with the 2019 novel coronavirus indicating person-to-person transmission: a study of a family cluster. Lancet 395(10223):514-523

2. Zhou P, Yang XL, Wang XG, Hu B, Zhang L, Zhang W et al (2020) A pneumonia outbreak associated with a new coronavirus of probable bat origin. Nature 579(7798):270-273

3. Zhu N, Zhang D, Wang W, Li X, Yang B, Song J et al (2020) A novel coronavirus from patients with pneumonia in China, 2019. N Engl J Med 382(8):727-733

4. WHO. Novel coronavirus situation dashboard. WHO, Geneva (2020).

5. World Health Organization. Coronavirus Disease (COVID-19) pandemic https://www.who.int/emergencies/diseases/novel-coron avirus-2019. Accessed 1 June 2020.

6. Lai CC, Wang CY, Wang YH, Hsueh SC, Ko WC, Hsueh PR (2020) Global epidemiology of coronavirus disease 2019 (COVID-19): disease incidence, daily cumulative index, mortality, and their association with country healthcare resources and economic status. Int J Antimicrob Agents 55(4): 105946

7. Wu C, Chen X, Cai Y, Xia J, Zhou X, Xu S et al (2020) Risk factors associated with acute respiratory distress syndrome and death in patients with coronavirus disease 2019 pneumonia in Wuhan, China. JAMA Intern Med 180:7-934

8. Yang X, Yu Y, Xu J, Shu H, Xia J, Liu H et al (2020) Clinical course and outcomes of critically ill patients with SARS-CoV-2 pneumonia in Wuhan, China: a single-centered, retrospective, observational study. Lancet Respir Med 8(5):475-481

9. Zhou F, Yu T, Du R, Fan G, Liu Y, Liu Z et al (2020) Clinical course and risk factors for mortality of adult inpatients with COVID-19 in Wuhan, China: a retrospective cohort study. Lancet 395(10229): 1054-1062

10. Zheng Z, Peng F, Xu B, Zhao J, Liu H, Peng J et al (2020) Risk factors of critical \& mortal COVID-19 cases: a systematic literature review and meta-analysis. J Infect 81:e16-e25

11. Higgins Julian TJ (2019) Cochrane handbook for systematic reviews of interventions. Version 6

12. Wells GSB, O'Connell D, Peterson J (2018) The NewcastleOttawa Scale (NOS) for assessing the quality of nonrandomised studies in meta-analyses 2000

13. Matthias Egger GDS, Martin S, Christoph M (1997) Bias in meta-analysis detected by a simple, graphical test. Br Med J 315(7109):629-634

14. Begg CB, Mazumdar M Operating characteristics of a rank correlation test for publication bias. (0006-341X (Print)) 
15. Higgins JPT, Thompson SG, Deeks JJ, Altman DG (2003) Measuring inconsistency in meta-analyses. BMJ 327(7414):557-560

16. Shi L, Lin L (2019) The trim-and-fill method for publication bias: practical guidelines and recommendations based on a large database of meta-analyses. Medicine (Baltimore). 98(23):e15987

17. Huang C, Wang Y, Li X, Ren L, Zhao J, Hu Y et al (2020) Clinical features of patients infected with 2019 novel coronavirus in Wuhan, China. Lancet 395(10223):497-506

18. Chen R, Liang W, Jiang M, Guan W, Zhan C, Wang T et al (2020) Risk factors of fatal outcome in hospitalized subjects with coronavirus disease 2019 from a nationwide analysis in China. Chest 158:97-105

19. Chen X, Zhao B, Qu Y, Chen Y, Xiong J, Feng Y et al (2020) Detectable serum SARS-CoV-2 viral load (RNAaemia) is closely correlated with drastically elevated interleukin 6 (IL-6) level in critically ill COVID-19 patients. Clin Infect Dis 14:3

20. Cheng Y, Luo R, Wang K, Zhang M, Wang Z, Dong L et al (2020) Kidney disease is associated with in-hospital death of patients with COVID-19. Kidney Int 97(5):829-838

21. Du RH, Liang LR, Yang CQ, Wang W, Cao TZ, Li M et al (2020) Predictors of mortality for patients with COVID-19 pneumonia caused by SARS-CoV-2: a prospective cohort study. Eur Respir J 55(5):2000524

22. Feng YA-O, Ling YA-O, Bai T, Xie YA-O, Huang J, Li J et al COVID-19 with different severities: a multicenter study of clinical features. (1535-4970 (Electronic))

23. Guan WJ, Liang WH, Zhao Y, Liang HR, Chen ZS, Li YM et al (2020) Comorbidity and its impact on 1590 patients with COVID19 in China: a nationwide analysis. Eur Respir J 55(5):2001227

24. Guan WJ, Ni ZY, Hu Y, Liang WH, Ou CQ, He JX et al (2020) Clinical characteristics of coronavirus disease 2019 in China. N Engl J Med 382(18):1708-1720

25. Ji D, Zhang D, Xu J, Chen Z, Yang T, Zhao P et al (2020) Prediction for progression risk in patients with COVID-19 pneumonia: the CALL Score. Clin Infect Dis 71:1393-1399

26. Li K, Wu J, Wu F, Guo D, Chen L, Fang Z et al (2020) The clinical and chest $\mathrm{CT}$ features associated with severe and critical COVID19 pneumonia. Investig Radiol 55(6):327-331

27. Li X, Xu S, Yu M, Wang K, Tao Y, Zhou Y et al (2020) Risk factors for severity and mortality in adult COVID-19 inpatients in Wuhan. J Allergy Clin Immunol 146:110-118

28. Li YK, Peng S, Li LQ, Wang Q, Ping W, Zhang N et al (2020) Clinical and transmission characteristics of Covid-19-a retrospective study of 25 cases from a single thoracic surgery department. Curr Med Sci 40(2):295-300

29. Liu R, Ma Q, Han H, Su H, Liu F, Wu K et al (2020) The value of urine biochemical parameters in the prediction of the severity of coronavirus disease 2019. Clin Chem Lab Med 58(7):1121-1124

30. Liu W, Tao ZW, Wang L, Yuan ML, Liu K, Zhou L et al (2020) Analysis of factors associated with disease outcomes in hospitalized patients with 2019 novel coronavirus disease. Chin Med J (Engl) 133(9):1032-1038

31. Liu Y, Sun W, Guo Y, Chen L, Zhang L, Zhao S et al (2020) Association between platelet parameters and mortality in coronavirus disease 2019: retrospective cohort study. Platelets 31(4):490-496

32. Mo P, Xing Y, Xiao Y, Deng L, Zhao Q, Wang H et al (2020) Clinical characteristics of refractory COVID-19 pneumonia in Wuhan, China. Clin Infect Dis

33. Qu R, Ling Y, Zhang YH, Wei LY, Chen X, Li XM et al (2020) Platelet-to-lymphocyte ratio is associated with prognosis in patients with coronavirus disease-19. J Med Virol 92:1533-1541

34. Shi Y, Yu X, Zhao H, Wang H, Zhao R, Sheng J (2020) Host susceptibility to severe COVID-19 and establishment of a host risk score: findings of 487 cases outside Wuhan. Crit Care 24(1):108
35. Tang N, Li D, Wang X, Sun Z (2020) Abnormal coagulation parameters are associated with poor prognosis in patients with novel coronavirus pneumonia. J Thromb Haemost 18(4):844-847

36. Tian S, Hu N, Lou J, Chen K, Kang X, Xiang Z et al (2020) Characteristics of COVID-19 infection in Beijing. J Infect 80(4):401-406

37. Wang D, Hu B, Hu C, Zhu F, Liu X, Zhang J et al (2020) Clinical characteristics of 138 hospitalized patients with 2019 novel coronavirus-infected pneumonia in Wuhan, China. JAMA 323:1061

38. Wang R, Pan M, Zhang X, Han M, Fan X, Zhao F et al (2020) Epidemiological and clinical features of 125 Hospitalized Patients with COVID-19 in Fuyang, Anhui, China. Int J Infect Dis 95:421-428

39. Wang Z, Yang B, Li Q, Wen L, Zhang R (2020) Clinical features of 69 cases with coronavirus disease 2019 in Wuhan, China. Clin Infect Dis 71:769-777

40. Wu J, Li W, Shi X, Chen Z, Jiang B, Liu J et al (2020) Early antiviral treatment contributes to alleviate the severity and improve the prognosis of patients with novel coronavirus disease (COVID19). J Intern Med 288(1):128-138

41. Yang AP, Liu JP, Tao WQ, Li HM (2020) The diagnostic and predictive role of NLR, d-NLR and PLR in COVID-19 patients. Int Immunopharmacol 84:106504

42. Yang X, Yang Q, Wang Y, Wu Y, Xu J, Yu Y et al (2020) Thrombocytopenia and its association with mortality in patients with COVID-19. J Thromb Haemost 18(6):1469-1472

43. Yuan M, Yin W, Tao Z, Tan W, Hu Y (2020) Association of radiologic findings with mortality of patients infected with 2019 novel coronavirus in Wuhan, China. PLoS ONE 15(3):e0230548

44. Zhang J, Wang X, Jia X, Li J, Hu K, Chen G et al (2020) Risk factors for disease severity, unimprovement, and mortality in COVID-19 patients in Wuhan, China. Clin Microbiol Infect 26(6):767-772

45. Parra-Bracamonte GM, Lopez-Villalobos N, Parra-Bracamonte FE (2020) Clinical characteristics and risk factors for mortality of patients with COVID-19 in a large data set from Mexico. Ann Epidemiol 52:93-98

46. Chang MC, Hwang JM, Jeon JH, Kwak SG, Park D, Moon JS (2020) Fasting plasma glucose level independently predicts the mortality of patients with coronavirus disease 2019 infection: a multicenter retrospective cohort study. Endocrinol Metab (Seoul) 35(3):595-601

47. Cai Q, Chen F, Wang T, Luo F, Liu X, Wu Q et al (2020) Obesity and COVID-19 Severity in a Designated Hospital in Shenzhen, China. Diabetes Care 43(7):1392-1398

48. Almazeedi S, Al-Youha S, Jamal MH, Al-Haddad M, Al-Muhaini A, Al-Ghimlas F et al (2020) Characteristics, risk factors and outcomes among the first consecutive 1096 patients diagnosed with COVID-19 in Kuwait. EClinicalMedicine. 24:100448

49. Feng Y, Ling Y, Bai T, Xie Y, Huang J, Li J et al (2020) COVID19 with different severities: a multicenter study of clinical features. Am J Respir Crit Care Med 201(11):1380-1388

50. Hussain A, Bhowmik B, do Vale Moreira NC (2020) COVID19 and diabetes: knowledge in progress. Diabetes Res Clin Pract 162:108142

51. Zhu L, She ZG, Cheng X, Qin JJ, Zhang XJ, Cai J et al (2020) Association of blood glucose control and outcomes in patients with COVID-19 and pre-existing type 2 diabetes. Cell Metab 31(6):1068-1077

52. Schoen K, Horvat N, Guerreiro NFC, de Castro I, de Giassi KS (2019) Spectrum of clinical and radiographic findings in patients with diagnosis of $\mathrm{H} 1 \mathrm{~N} 1$ and correlation with clinical severity. BMC Infect Dis 19(1):964 
53. Yang JK, Feng Y, Yuan MY, Yuan SY, Fu HJ, Wu BY et al (2006) Plasma glucose levels and diabetes are independent predictors for mortality and morbidity in patients with SARS. Diabet Med 23(6):623-628

54. Banik GR, Alqahtani AS, Booy R, Rashid H (2016) Risk factors for severity and mortality in patients with MERS-CoV: analysis of publicly available data from Saudi Arabia. Virol Sin 31(1):81-84

55. Gheblawi M, Wang K, Viveiros A, Nguyen Q, Zhong JC, Turner AJ et al (2020) Angiotensin-converting enzyme 2: SARS-CoV-2 receptor and regulator of the renin-angiotensin system: celebrating the 20th anniversary of the discovery of ACE2. Circ Res 126(10):1456-1474

56. Hoffmann M, Kleine-Weber H, Schroeder S, Kruger N, Herrler T, Erichsen S et al (2020) SARS-CoV-2 cell entry depends on ACE2 and TMPRSS2 and is blocked by a clinically proven protease inhibitor. Cell 181(2):271-280

57. Lan J, Ge J, Yu J, Shan S, Zhou H, Fan S et al (2020) Structure of the SARS-CoV-2 spike receptor-binding domain bound to the ACE2 receptor. Nature 581(7807):215-220

58. Pascarella G, Strumia A, Piliego C, Bruno F, Del Buono R, Costa $F$ et al (2020) COVID-19 diagnosis and management: a comprehensive review. J Intern Med 288(2):192-206

59. Yan R, Zhang Y, Li Y, Xia L, Guo Y, Zhou Q (2020) Structural basis for the recognition of SARS-CoV-2 by full-length human ACE2. Science (New York, NY). 367(6485):1444-1448

60. Alenina N, Bader M (2019) ACE2 in brain physiology and pathophysiology: evidence from transgenic animal models. Neurochem Res 44(6):1323-1329

61. Santos RAS, Sampaio WO, Alzamora AC, Motta-Santos D, Alenina N, Bader M et al (2018) The ACE2/Angiotensin-(1-7)/ MAS axis of the renin-angiotensin system: focus on angiotensin-(1-7). Physiol Rev 98(1):505-553

62. Asadi-Pooya AA, Simani L (2020) Central nervous system manifestations of COVID-19: a systematic review. J Neurol Sci 413:116832

63. Pei G, Zhang Z, Peng J, Liu L, Zhang C, Yu C et al (2020) Renal involvement and early prognosis in patients with COVID-19 pneumonia. J Am Soc Nephrol 31(6):1157-1165
64. Ronco C, Reis T, Husain-Syed F (2020) Management of acute kidney injury in patients with COVID-19. Lancet Respir Med 8(7):738-742

65. Zhang L, Zhu F, Xie L, Wang C, Wang J, Chen R et al (2020) Clinical characteristics of COVID-19-infected cancer patients: a retrospective case study in three hospitals within Wuhan, China. Ann Oncol 31(7):894-901

66. Gosain R, Abdou Y, Singh A, Rana N, Puzanov I, Ernstoff MS (2020) COVID-19 and cancer: a comprehensive review. Curr Oncol Rep 22(5):53

67. Giamarellos-Bourboulis EJ, Netea MG, Rovina N, Akinosoglou $\mathrm{K}$, Antoniadou A, Antonakos N et al (2020) Complex immune dysregulation in COVID-19 patients with severe respiratory failure. Cell Host Microbe 27(6):992-1000

68. Vardhana SA, Wolchok JD (2020) The many faces of the antiCOVID immune response. J Exp Med 217(6):e20200678

69. Tian S, Hu W, Niu L, Liu H, Xu H, Xiao SY (2020) Pulmonary pathology of early-phase 2019 novel coronavirus (COVID-19) pneumonia in two patients with lung cancer. $J$ Thorac Oncol 15(5):700-704

70. Lechien JR, Chiesa-Estomba CM, Place S, Van Laethem Y, Cabaraux P, Mat Q et al (2020) Clinical and epidemiological characteristics of 1420 European patients with mild-to-moderate coronavirus disease 2019. J Intern Med 288(3):335-344

71. Sproston NR, Ashworth JJ (2018) Role of C-reactive protein at sites of inflammation and infection. Front Immunol 9:754

72. Ngwa DN, Agrawal A (2019) Structure-function relationships of C-reactive protein in bacterial infection. Front Immunol 10:166

73. Du Clos TW, Mold C (2001) The role of C-reactive protein in the resolution of bacterial infection. Curr Opin Infect Dis 14(3):289-293

74. Li Y, Yang Z, Ai T, Wu S, Xia L (2020) Association of "initial CT" findings with mortality in older patients with coronavirus disease 2019 (COVID-19). Eur Radiol 30(11):6186-6193

Publisher's Note Springer Nature remains neutral with regard to jurisdictional claims in published maps and institutional affiliations. 